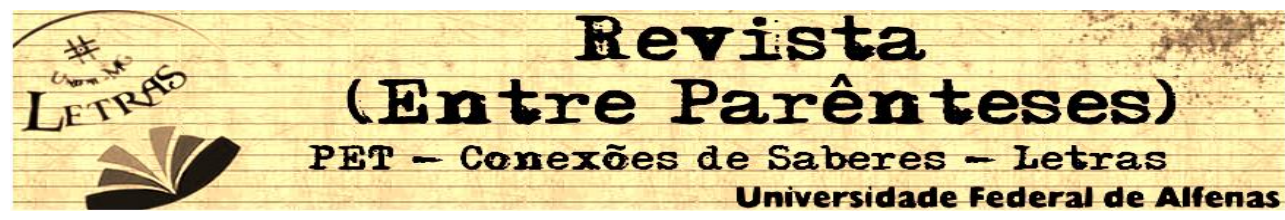

\title{
Estudo do Falar de Paraguaçu, MG e Região: Expressões Idiomáticas
}

\author{
Silmara Luiza Órfão Novais ${ }^{1}$ \\ Universidade Federal de Alfenas \\ silmaraluizanovais@live.com \\ Celso Ferrarezi Júnior ${ }^{2}$ \\ Universidade Federal de Alfenas \\ cferrarezij@superig.com
}

Resumo: Levando-se em conta que um povo é carregado de sua cultura, consequentemente, o falar deste povo é marcado pelas tradições culturais de muitos anos. Como diz Ferrarezi (2013), "A linguagem congrega um sem-número de características culturais do povo que a fala (...)". Assim, foram feitas pesquisas e coletas de expressões idiomáticas na região de Paraguaçu/MG e seus entornos, descobrindo-se uma diversidade de expressões muito faladas e outras já moribundas entre os falantes. Peculiarmente, as expressões aqui registradas são de comum uso dos falantes desta região, sendo de difícil compreensão para as pessoas que não fazem parte dela.

Palavras-chave: Linguagem identitária. Semântica Cultural. Expressões Idiomáticas. Falares regionais. Paraguaçu, MG.

Abstract: Taking into account that a people is marked by their culture, hence the talking of this people is marked by the cultural traditions of many years. As Ferrarezi (2013) says "The language brings together a multitude of cultural characteristics of the people who speak (...)". Thus, research and collections of idiomatic expressions were made in the region of Paraguaçu/MG and their surroundings, discovering a diversity of expressions and other spoken, much already dying between speakers. Peculiarly, the expressions registered here are in common use by speakers of this region, being difficult to understand for people who are not part of it.

Key-Words: Language identify tags. Cultural Semantics. Idioms. Regional speaking. Paraguaçu, MG, Brazil.

\footnotetext{
${ }^{1}$ Graduanda em Letras. Membro do Grupo de Pesquisas Linguísticas Descritivas, Teóricas e Aplicadas. Desenvolve projeto de Iniciação Científica Voluntária.

2Orientador. Professor do Instituto de Ciências Humanas e Letras da UNIFAL-MG. Coordenador do Grupo de Pesquisas Linguísticas Descritivas, Teóricas e Aplicadas - GP-Lin.
} 


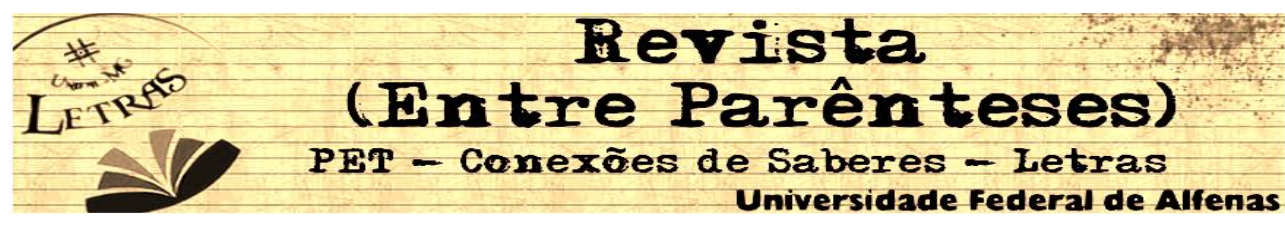

\section{Introdução}

O presente estudo do falar regional de Paraguaçu (MG) e região se constituiu na coleta do léxico idiomático (palavras e expressões) que caracterizam o falar das comunidades pesquisadas e na sua análise com base na metodologia da Semântica de Contextos e Cenários - SCC.

Na cidade de Paraguaçu, localizada no interior de Minas Gerais, vive um povo marcado pela simplicidade e carregado de tradições. Dentre essas tradições, curiosamente, está o fato de que os falantes mantêm um grande vocabulário de expressões idiomáticas, muito utilizadas oralmente e que só são compreendidas pelos próprios falantes deste lugar. Algumas expressões já se encontram em estado moribundo e marcam a cultura simples e carregada de valores que este povo conserva como tradição, caso típico entre as cidades interioranas nesta região. A necessidade de se fazer este estudo de forma urgente se deu pelo fato do avanço muito acelerado das tecnologias de comunicação que têm levado, principalmente os jovens, a perder essa identidade linguística em um processo muito acelerado. Desta forma, acredita-se que o estudo dessas expressões possa servir, ao menos, como registro histórico-cultural desse falar tão rico.

Assim sendo, nosso objetivo dou o de registrar o maior número de palavras e expressões idiomáticas possível, peculiarmente relativas ao povo de Paraguaçu (MG) e seu entorno, promovendo uma descrição semântico-cultural, com o objetivo de descrever e analisar os aspectos culturais e identitários presentes no falar deste povo.

\section{Aspectos teóricos da pesquisa}

Para dar conta de uma pesquisa com um viés cultural tão marcado, optamos por utilizar a Semântica de Contextos e Cenários (Ferrarezi, 2010). Um aspecto importante a ressaltar sobre este referencial é que a Semântica Cultural está em fase de implantação e divulgação no Brasil, sendo possível encontrar assim, poucos 


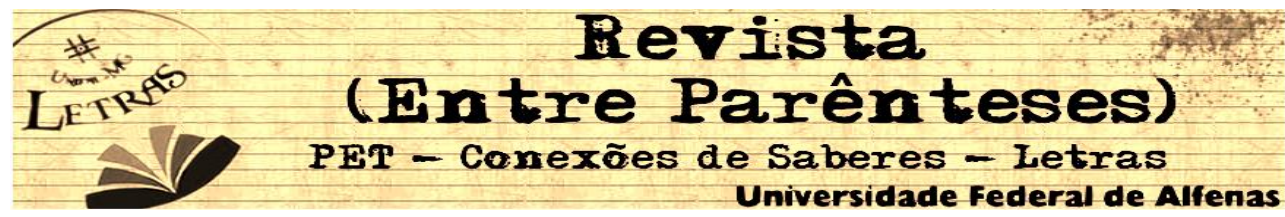

teóricos e referenciais. Desta forma, me fundamento basicamente em Ferrarezi Jr. e seu livro "Introdução à Semântica de Contextos e Cenários: de La langue à la vie" (2010) .

Partindo do pressuposto de que língua e cultura são vinculadas uma a outra, adoto o conceito de língua da Semântica de Contexto e Cenários - SCC, que segundo Ferrarezi (2010) "[...] é um sistema socializado e culturalmente determinado de representação de mundos e seus eventos (...)".

Podemos compreender assim, que a língua tem duas dimensões: a dimensão dos pensamentos e da visão de mundo dos falantes, construída por meio e entremeada com a construção cultural de cada comunidade (onde se inserem os significados) e a dimensão propriamente linguística, manifestação da primeira (onde se inserem os sentidos). Com base nisso, a SCC entende que é mais pertinente estudar as manifestações linguísticas do significado (sentidos) pois, conforme Ferrarezi Jr.:

Se o significado não é objeto do estudo da Semântica, mas suas manifestações é que o são - quais sejam elas - as múltiplas formas pelas quais a língua o manifesta em seu sistema e nas funções para as quais esse sistema foi criado (...) podemos confirmar a adoção do termo "sentido", que me parece ser, na literatura corrente, aquele que mais se aproxima da ideia que pretendo expressar quando falo de manifestações linguísticas do significado (...). (idem, p.59)

No âmbito da Semântica Cultural, entretanto, as expressões idiomáticas, surgem pela necessidade de se definir novos sentidos na fala e, obrigatoriamente, isso se dá por intermédio da cultura como fator determinante, representando os valores de uma comunidade.

Desta forma, podemos entender que a língua pode ser considerada como uma forma de estabelecimento da identidade de um povo e que palavras e expressões peculiares de uma comunidade atuam como marcas identitárias de uma sociedade e de seus indivíduos. E, ainda, podemos inferir que a língua não é "autônoma", pois ela se relaciona estritamente com a cultura influenciando, sendo 


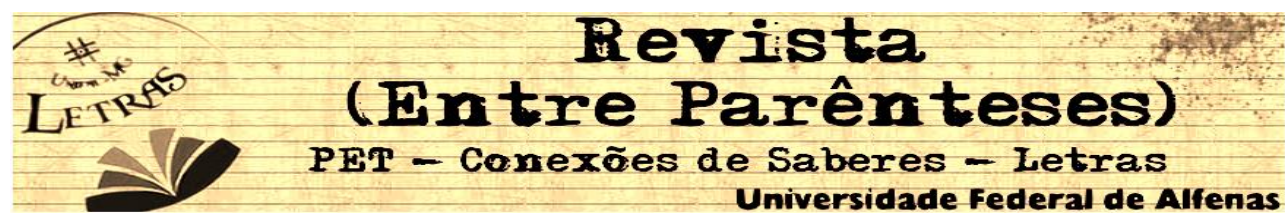

influenciada e revelando construções e usos que os falantes delas fazem. Em outras palavras, a cultura é a base; a língua nasce dela e com ela, e nela sobrevive.

Segundo Geertz (2011, p. 50) podemos entender a cultura como: "um sistema ordenado de significado e símbolos... nos termos dos quais os indivíduos definem seu mundo, expressam seus sentimentos e fazem seus julgamentos". Complementando este conceito Geertz (op. cit, p. 60) defende que: "[...] os recursos culturais são ingredientes, e não acessórios, do pensamento humano".

Como vimos que a língua se manifesta através da cultura e nela tem sua base, podemos usar como conceito para as expressões idiomáticas, as definições que Rocha (2012) faz quando fala que:

Entendemos por expressão idiomática, uma unidade lexical que não pode ser compreendida mediante a decomposição de seus termos, visto que seu sentido não é a somatória do significado dos elementos que a constituem, conforme a proposta por Tagnin (1988). Para Xatara (1998) as expressões idiomáticas são constituídas por expressões metafóricas e metonímicas que as distanciam de um sentido literal e revelam um mundo simbólico que exprime julgamentos sociais.

Podemos preconizar então, que a linguagem, o pensamento e a cultura, estão interligados nas expressões idiomáticas, formando um grande emaranhado de conhecimentos e identificando a maneira de comunicação de um determinado povo.

Vale ressaltar que, a despeito de suas aparentes exceções gramaticais, as expressões idiomáticas entram na construção de formas mais amplas da língua, apresentam uma estruturação lógica e processos de constituição já bem conhecidos e não são fruto de um acaso pervertido que desbanca a pureza das línguas oficiais. Ao contrário disso, são o resultado de um conjunto de processos bastante produtivos em qualquer comunidade de falantes, que acaba por estabelecer traços morfossintáticos muito próprios que passam a atuar como elementos diferenciadores daquela comunidade, ou seja, elementos linguísticos que passam a atuar como marcas identitárias. 


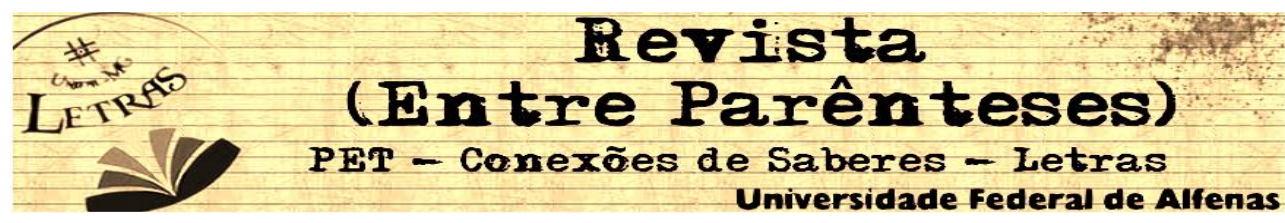

\section{A pesquisa}

Como a língua é um universo de complexidades e é algo permanentemente inacabado, ela está em constantes transformações. Nesse meio de transformações, existem inovações e "desaparecimentos". Assim, palavras e expressões surgem e morrem, o que pode acontecer em longos períodos ou em pouco tempo. Isso se dá principalmente na fala, pois as necessidades da comunicação levam os falantes a criar novas palavras e expressões. Segundo Ferrarezi (2010),

Sausurre, por exemplo, alude aos fatos de que a fala é muito mais dinâmica que a escrita e, por isso mesmo, regida por princípios distintos, o que legava à fala, segundo ele, um valor superior ao da escrita como objeto de estudo da Linguística, uma vez que ela refletiria de forma mais fiel a evolução de uma língua natural. (p.25).

Neste sentido, ao se fazer um estudo sobre as expressões idiomáticas da cidade de Paraguaçu e região, demos prioridade à fala da comunidade como desenvolvida pelos falantes.

A coleta dos dados para a pesquisa se deu pela observação das conversações livres entre falantes em ambientes públicos, onde transitavam muitas pessoas e não por meio de entrevistas estruturadas, de forma que os dados colhidos são sempre espontâneos, ligados ao cotidiano das pessoas e gerados de forma livre. As expressões coletadas foram registradas em lugares simples do cotidiano, como supermercados, feira municipal, nas ruas e em diversos outros lugares, sendo que todos os dados foram anotados sem nenhuma interferência da pesquisadora em relação aos falantes.

Em um período de um ano, pudemos registrar um número de quarenta expressões idiomáticas do falar de Paraguaçu (MG) e seus entornos. Após os registros de campo, foi realizada, com essas expressões, uma classificação por ordem alfabética, e cada uma foi classificada ainda, por número de identificação do dado, data de coleta, contexto imediato, cenário e sentido. 


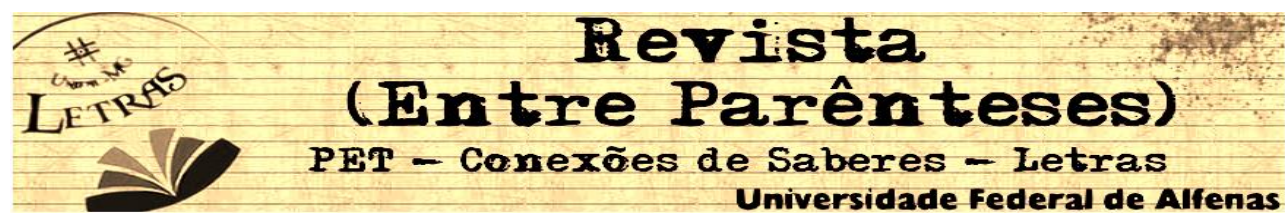

Além disso, foi realizada na região, uma pesquisa das possíveis fontes escritas sobre o tema, se alguém já havia estudado as expressões idiomáticas ali faladas. No entanto, não encontramos nenhum registro de atividades deste tipo ou semelhantes. Foi possível localizar alguns registros de variações linguísticas, mais propriamente ditos do "caipirês" da região. Encontramos também, muitos relatos em jornais e revistas regionais, brincando com a fala tratada preconceituosamente como "errada" e "caipira", que é muito comum entre os moradores da região.

Foi possível observar ainda, por informações orais, que houve alguns poucos registros das expressões idiomáticas regionais feitos pelo falecido advogado, senhor Marcos Vinícius Ribeiro Dias, nascido em Machado/MG e "naturalizado" informalmente em Paraguaçu/MG. Ele escreveu, um livro em 1996, que ganhou o nome "Humor na Marolândia", em que conta muitas anedotas e "causos" que ouviu do povo paraguaçuense. Mas, ao fazermos a leitura de seu livro, pudemos perceber que não há registro de expressões idiomáticas, propriamente ditas, mas apenas registro de diferentes palavras escritas de forma estigmatizada pela variação linguística, tais como: "rapaizinho disgraçado prá robá tá aí!" (p. 34); "Quando chegá na cidade, só vô tê um pobrema, é contá prô Padre meus treis ou quatro pecado." ou "É, mais ainda farta umas cinco ou seis légua morde nóis chegá..." (p. 22).

Diante da ausência absoluta de fontes escritas de registro, tivemos que nos ater apenas às falas espontâneas e, partindo dessa restrição, tentamos registrar o maior número dessas expressões do falar regional que conseguimos pela observação aberta do falar local.

É importante lembrar aqui, que, segundo Ferrarezi (2010, p. 68), "cada cultura cria hierarquias classificatórias do mundo que servem para a organização desse mundo pelos 'olhos' de cada cultura." Deste modo, os significados das expressões que registramos ao longo deste trabalho, podem ter outros significados ou nem existir em outras culturas.

Vale de registrar, também, que por meio de tais expressões, podemos conhecer um pouco da cultura de um povo e o sentido que as palavras têm ou tiveram em seu meio, como encontramos em Ferrarezi (2010, p. 81): "Se alguma relação há entre as palavras e sentidos, essa relação é cultural, atribuída pelo 


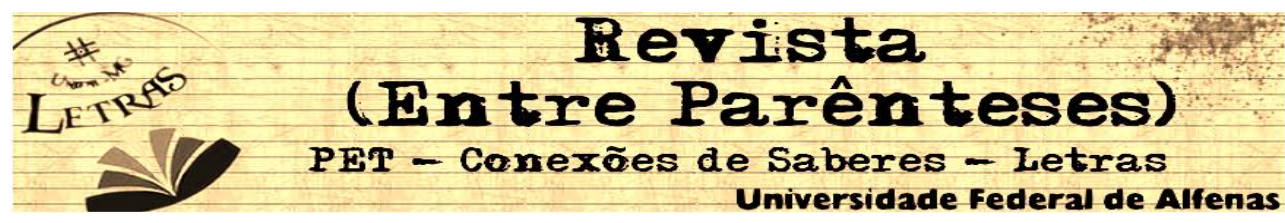

habitus linguístico, por costume e não por propriedades das palavras ou dos sentidos."

\section{Amostra de resultados}

Passamos, agora, à análise de algumas das expressões registradas, focando no sentido que a elas foi atribuído no uso cotidiano. Pode-se verificar que essas palavras e expressões apresentam, como é típico de expressões idiomáticas, sentidos outros que não aqueles costumeiros de cada palavra isoladamente em seu uso cotidiano. Isso permite a construção de sentidos complexos que só são identificáveis por quem comunga da cultura popular regional e, por isso, acabam funcionando como marcas de identidade dos falantes locais.

As expressões são apresentadas aqui em quadros de registro próprios da metodologia de coleta de dados da SCC, que constam o dado, a identificação da data e local, o contexto em que a expressão aparece, o cenário em que o dado foi produzido e o sentido atribuído pelo falante ou pelos falantes da região. Esse conjunto de informações permite reconstruir de forma mais precisa a leitura de mundo feita pelos interlocutores na ocasião de produção do dado e ajuda a compreender mais profundamente aspectos de sentido que cooperam para sua compreensão cultural.

Vejamos alguns exemplos comentados, selecionados dentre o conjunto total de expressões colhidas durante a pesquisa:

\section{Quadro 1: Bão-pra-sabão}

\begin{tabular}{|c|c|c|c|c|}
\hline Dado & & Sontexto & Cenário & \\
\hline $\begin{array}{l}\text { Bão- } \\
\text { pra- } \\
\text { sabão }\end{array}$ & $\begin{array}{l}\text { 18/02/2014 } \\
\text { Paraguaçu/MG, } \\
\text { na praça } \\
\text { central } \\
\text { cidade. }\end{array}$ & 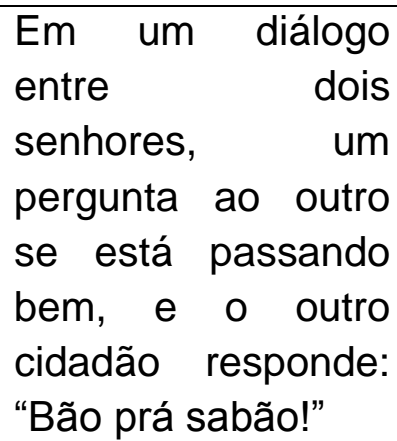 & $\begin{array}{l}\text { Diálogo } \\
\text { informal entre } \\
\text { dois senhores } \\
\text { idosos } \\
\text { sentados em } \\
\text { um banco da } \\
\text { praça central } \\
\text { da cidade. }\end{array}$ & $\begin{array}{l}\text { Velho } r \\
\text { desgastado como } \\
\text { gordura que se } \\
\text { usa para fazer } \\
\text { sabão caseiro, } \\
\text { mas ainda } \\
\text { servindo para } \\
\text { alguma coisa. }\end{array}$ \\
\hline
\end{tabular}




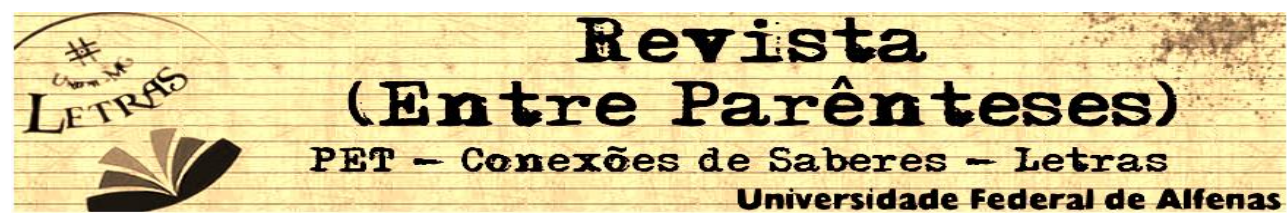

A expressão "bão-pra-sabão" foi coletada no centro da cidade, casualmente, a partir da conversa de senhores idosos que estavam na praça central da cidade. É muito rara esta expressão e só é usada por pessoas mais velhas. Ela foi usada para se referir à idade avançada e o tempo de velhice dos idosos que a falaram. Com esta expressão eles queriam expressar que estavam tão velhos quanto a gordura já usada que é reutilizada para fazer o sabão caseiro, prática muito comum na cidade. Trata-se de uma metáfora evidente, que enfoca o fato de que, apesar de velho e desgastado, o sujeito/ a coisa ainda é útil para algo. A expressão aparece em outros contextos de uso, a saber: "Estou velho e bão-pra-sabão." / "Isso está bão-pra-sabão de tão gasto que está.", sempre com o mesmo sentido, mas ora aplicada a pessoas ou animais, ora aplicada a coisas.

Quadro 2: Enrabichou na moto

\begin{tabular}{|c|c|c|c|c|}
\hline Dado & Data / Local & Contexto & Cenário & Sentido \\
\hline $\begin{array}{l}\text { Enrabichou } \\
\text { na moto }\end{array}$ & $\begin{array}{l}\text { 02/12/2013 } \\
\text { Paraguaçu/MG } \\
\text { Um idoso na } \\
\text { rua } \\
\text { observando } \\
\text { dois } \\
\text { namorados } \\
\text { que andam de } \\
\text { motocicleta. }\end{array}$ & $\begin{array}{l}\text { "A moça já } \\
\text { enrabichou } \\
\text { na moto." }\end{array}$ & $\begin{array}{l}\text { Fala de um } \\
\text { idoso transeunte } \\
\text { da rua, ao } \\
\text { observar a ação } \\
\text { de uma mulher } \\
\text { segurar no tórax } \\
\text { de seu } \\
\text { namorado } \\
\text { quando os dois } \\
\text { saíram com a } \\
\text { motocicleta } \\
\text { ligada. }\end{array}$ & $\begin{array}{l}\text { Agarrou, segurou } \\
\text { de maneira } \\
\text { "incorreta" e "sem } \\
\text { pudor" em seu } \\
\text { namorado, ao subir } \\
\text { na motocicleta. } \\
\text { Obs: A expressão } \\
\text { tem tom de crítica } \\
\text { ética. Seu uso é } \\
\text { mais comum } \\
\text { quando o falante se } \\
\text { sente incomodado } \\
\text { ao ver a atitude } \\
\text { "vergonhosa" de } \\
\text { uma mulher na } \\
\text { garupa de uma } \\
\text { motocicleta pilotada } \\
\text { por um homem. }\end{array}$ \\
\hline
\end{tabular}




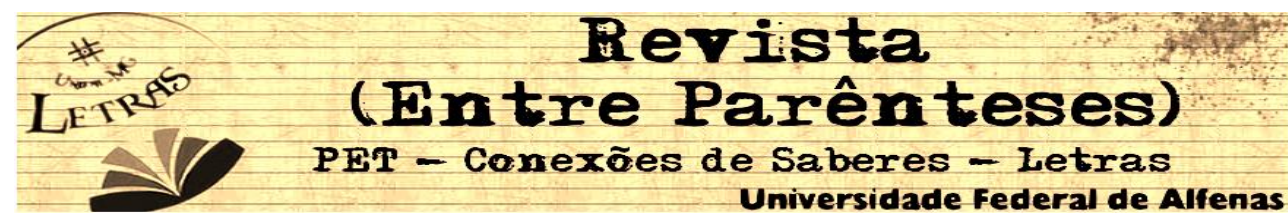

A expressão "Enrabichou na moto" foi coletada no centro da cidade, casualmente, da fala de um senhor que se escandalizou ao ver um casal de namorados ficarem com o corpo muito próximo ao subirem em uma motocicleta. É costumeiramente ouvida entre os falantes. Pode significar estar muito próximo ou ficar sempre atrás de uma pessoa, seguindo-a, ou simplesmente ficar muito tempo perto de alguém. "Enrabichar" é, assim, normalmente utilizado com a ideia de tomar a posição do "rabo" ou "rabicho" o que, em última instância, é uma metáfora que indica excessiva proximidade física. Nesse sentido, aparece costumeiramente em exemplos como: "O filho já enrabichou com o pai, não larga dele por nada." ou "Os dois amigos ficaram enrabichados as férias todas.". Como o advento do uso de motocicletas pelos mais jovens, especialmente de motocicletas esportivas que demandam uma postura sensual e "empinada" do garupa, que acaba se debruçando por sobre o piloto, o verbo passa a constituir uma expressão mais específica ("enrabichar na moto") e esta passa a ser utilizada pelos mais idosos em tom de crítica ética (e moral) direcionada ao comportamento das moças que se enrabicham com os namorados de forma considerada indecente.

Ilustração 1: "Enrabichou na moto"

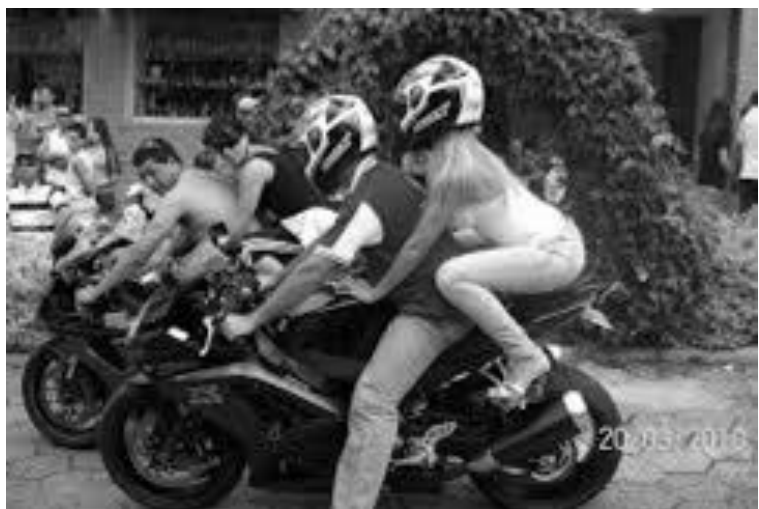

Fonte: www.hondacbrclubebrasil.com.br, acessado em 22 out. 2014.

Quadro 3: Esmoída

\begin{tabular}{|l|l|l|l|l|}
\hline Dado & Data / Local & Contexto & Cenário & Sentido \\
\hline Estou & $12 / 03 / 2014$ & "De tanto & Diálogo entre pessoas & Estar \\
esmoída & Paraguaçu/MG & trabalhar & na rua, que relatam & extremamente \\
& $\begin{array}{l}\text { Diálogo de de } \\
\text { adultos na rua. }\end{array}$ & estou & ter trabalhado & esgotado de \\
& esmoída." & demasiadamente. & trabalhar. \\
\hline
\end{tabular}




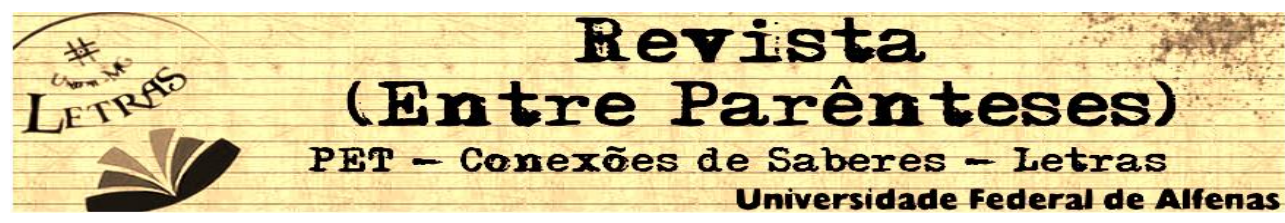

A expressão "Estou esmoída" foi coletada também casualmente, a partir de uma conversa de adultos que iam embora do trabalho e comentavam o quanto estavam cansados. É uma expressão muito comum. Ela é usada para designar um cansaço extremo. Sua origem cultural é desconhecida, porém, foi acrescentado o início "es" à palavra "moída", talvez para referir a um sentido intenso e negativo de "moído", ou seja, ficar muito cansado. Pode se tratar de uma analogia morfológica com outras palavras como "estragado", “esmagado”, “esfarrapado”, “estressado", "esquecido", "esganado" e "estropiado" entre outras, que têm sentido negativo e iniciam todas com "es", sendo parte do vocabulário local. Essa analogia é difícil de ser comprovada, mas tem como base outras ocorrências como "esturdido", ao invés de "aturdido", "estrofiado", ao invés de "atrofiado" e "estrapaiado", ao invés de "atrapalhado", que também ocorrem na macroregião, têm sentido negativo e não podem ser morfologicamente explicadas a partir dos vocábulos originais. Assim, a impressão que se tem é que os falantes preferem o início "es" como se fosse algum tipo de "prefixo" que indica, ao mesmo tempo, os sentidos de "excesso" e de "algo negativo". Outros exemplos em que aparece esta expressão são: "Trabalhei tanto que fiquei esmoída." e "Vou me deitar que já estou esmoída."

Quadro 4: Patuá à mostra

\begin{tabular}{|c|c|c|c|c|}
\hline Dado & Data / Local & Contexto & Cenário & Sentido \\
\hline $\begin{array}{l}\text { Patuá } \\
\text { à } \\
\text { mostra }\end{array}$ & $\begin{array}{l}\text { 25/08/2014 } \\
\text { Paraguaçu/MG } \\
\text { Em conversa } \\
\text { com amigos } \\
\text { pessoais }\end{array}$ & $\begin{array}{l}\text { "Ele está com } \\
0 \text { patuá à } \\
\text { mostra, como } \\
\text { não tem } \\
\text { vergonha?" }\end{array}$ & $\begin{array}{l}\text { Expressão } \\
\text { por usada } \\
\text { quando amigos } \\
\text { referiam a um } \\
\text { rapaz de casal de } \\
\text { jovens namorados } \\
\text { que passavam na } \\
\text { rua. }\end{array}$ & $\begin{array}{l}\text { Patuá significa o } \\
\text { membro fálico do } \\
\text { homem, } \\
\text { especialmente em } \\
\text { estado ereto. }\end{array}$ \\
\hline
\end{tabular}

A expressão "Patuá à mostra" foi coletada em conversa informal com amigos. É uma expressão um pouco mais rara. Ela foi usada referindo-se ao órgão genital masculino estando ereto, causando certo volume na parte frontal da calça de 


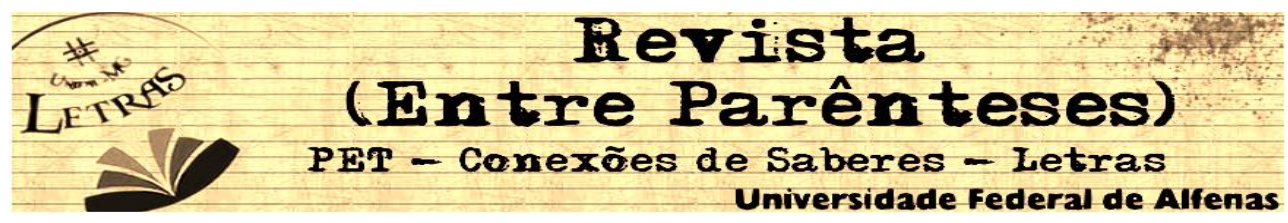

um jovem. Nessa forma, a expressão foi usada para se referir ao homem em ereção mas, isolada, a palavra "patuá" pode ser utilizada para se referir ao pênis de forma geral. Sua provável origem cultural vem do candomblé em que o patuá é uma espécie de amuleto de sorte feito de tecido colorido recheado com ervas sagradas que costumeiramente é levado no bolso para se obter proteção contra o mal. A metáfora que se constrói entre o pênis como um amuleto e o patuá de se levar no bolso (no caso específico, no bolso da calça) é clara. Outros exemplos em que a metáfora ocorre são: "Lá vem aquele rapaz do patuá grande." e "Como ele não tem vergonha de deixar todos verem como está seu patuá?"

llustração 2: Patuá

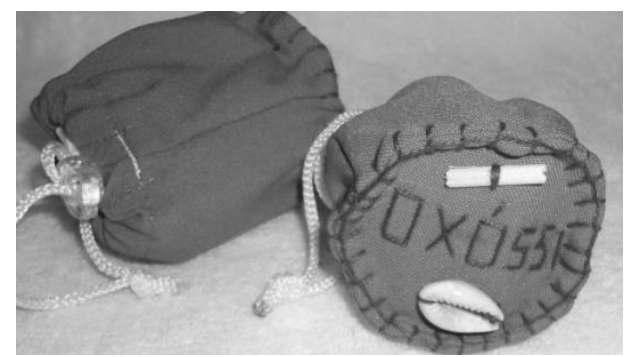

Fonte: www.batebumbo.com.br, acessado em 22 out. 2014.

\section{Quadro 5: Viu a viola em caco}

\begin{tabular}{|c|c|c|c|c|}
\hline Dado & Data / Local & Contexto & Cenário & Sentido \\
\hline $\begin{array}{l}\text { Viu a } \\
\text { viola } \\
\text { em } \\
\text { caco }\end{array}$ & $\begin{array}{l}17 / 02 / 2014 \\
\text { Paraguaçu/MG } \\
\text { Diálogo entre } \\
\text { idosos na rua. }\end{array}$ & $\begin{array}{l}\text { "Você viu a } \\
\text { viola em } \\
\text { caco dessa } \\
\text { vez." }\end{array}$ & $\begin{array}{lr}\text { Diálogo } & \text { entre } \\
\text { senhores na rua, que } \\
\text { contavam } & \text { sobre } \\
\text { enfermidades } & \text { que } \\
\text { tinham } & \text { passado } \\
\text { recentemente. } & \end{array}$ & $\begin{array}{lr}\text { Ver a viola em } \\
\text { caco é ver se } \\
\text { aproximar } \\
\text { morte diante de } \\
\text { uma } \quad \text { grave } \\
\text { situação } \\
\text { saúde. }\end{array}$ \\
\hline
\end{tabular}

A expressão "Viu a viola em caco" foi coletada em um diálogo entre senhores na rua, em que um deles comentava como conseguira sair do hospital. É uma expressão costumeira na região e é mais usada entre os moradores da zona 


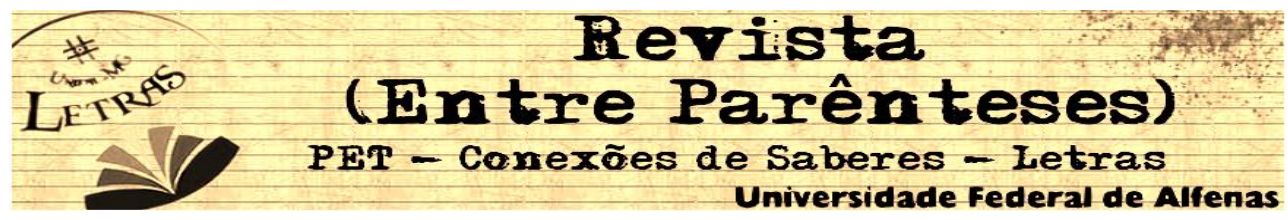

rural. Foi usada no sentido de ver se aproximar a morte diante de uma grave situação de saúde. Ela tende a expressar a ideia de "ver a morte se aproximando". Sua origem cultural é provavelmente relacionada ao costume do uso da viola como principal instrumento musical da região e a metáfora que se constrói entre a viola quebrada (em cacos) e a vida terminando é bastante reveladora (viola em cacos não toca mais). Outros exemplos: "Adoeci tanto que, dessa vez, vi a viola em caco." e "Vi a viola em caco naquele acidente."

\section{Considerações finais}

Embora existam poucos estudos sobre as expressões idiomáticas e 0 cenário cultural que as embasa, seu registro é relevante considerando-se que essas culturas regionais estão em forte e acelerada mudança gerada pela pressão dos meios de comunicação sobre as novas gerações. O que hoje é peculiar e identitário, amanhã pode ter virado história com o passamento das gerações mais tradicionais. O registro sistemático dessas expressões permitirá, ao menos, a construção de uma memória permanente dessa riqueza linguística, bem como a valorização do falar desse povo com preservação mesmo que "enciclopédica" dessa riqueza linguísticacultural.

As marcas linguísticas e identitárias são riqueza de um povo. Segundo Ferrarezi (2013, p. 1), “(...) a língua é mais do que um mero sistema de comunicação e funciona como um depósito das experiências culturais de uma comunidade (...)". Assim, cada povo constrói e carrega em sua língua diferenças, tanto nos costumes, quanto nos falares, que não podem ser desprezadas e não devem ser perdidas. Afinal, cada povo tem valores diferentes manifestos de forma peculiar.

\section{Referências bibliográficas}

FARACO, Carlos Alberto. Linguagem e Diálogo - As Ideias Linguísticas do Círculo de Bakhtin. São Paulo: Parábola Editorial, 2009. 


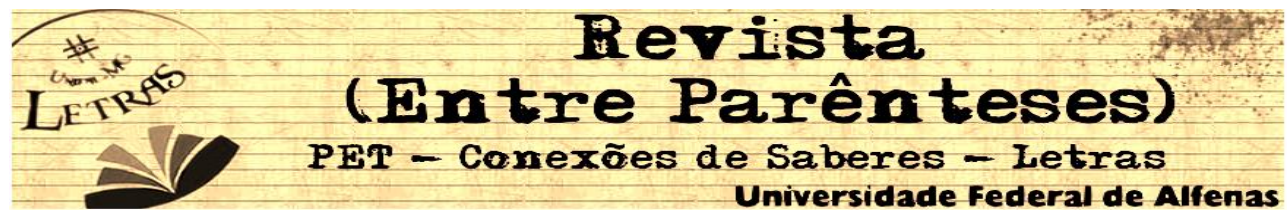

FERRAREZI Jr., C. "Quando só de para andando: minúsculo estudo de expressões idiomáticas de Guajará-Mirim, RO” In.: Práticas Discursivas Amazônicas: Ano 2, nº $2\left(1^{\circ}\right.$ Sem.2013). s.ed.: Cacoal, RO.

FERRAREZI Jr., C. Guia do Trabalho Científico: Do projeto à redação final. São Paulo, Contexto, 2013.

FERRAREZI Jr., Celso. Introdução à Semântica de Contextos e Cenários: de la langue à la vie. Campinas, SP: Mercado de Letras, 2010.

GEERTZ, Clifford. A interpretação das culturas. $1^{\text {a }}$ Ed. (Reimpr.). Rio de Janeiro: LTC, 2011.

RAJAGOPALAN, Kanavillil. A nova pragmática: fases e feições de um fazer. São Paulo: Parábola Editorial, 2010.

ROCHA, Camila Correa. "A formação do português brasileiro pela observação de expressões idiomáticas.” Disponível em:

<http://periodicos.pucminas.br/index.php/contraponto/article/view/4788 >. Acesso em 15 set. 2014.

SARDINHA, Tony Berber. Metáfora. São Paulo: Parábola Editorial, 2007. 